\title{
Recent Advances on Al-Sn Alloys with Ternary Alloying Elements
}

\author{
Satyanarayan $^{1 *}$ and Jayaram Bhat ${ }^{1,2}$ \\ ${ }^{1}$ Department of Mechanical Engineering, India \\ ${ }^{2}$ Department of Mechanical Engineering, India \\ *Corresponding author: Satyanarayan, Department of Mechanical Engineering, Moodbidri-574225, India
}

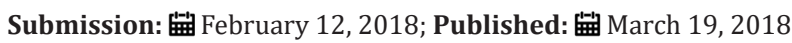

\begin{abstract}
Al-Sn alloys are preferred for bearing materials where an excellent lubricity with proper wear resistance is necessary. In the current paper, the key issues and improvements of $\mathrm{Al}-\mathrm{Sn}-\mathrm{X}(\mathrm{X}=\mathrm{Bi}, \mathrm{Mg}, \mathrm{Si}, \mathrm{Cu}, \mathrm{Pb})$ alloys are outlined. Effect of ternary alloying element $\mathrm{X})$ on microstructure, mechanical and tribological properties for Al-Sn alloys are reviewed in brief. Implementation and further development of Al-Sn-X alloys are to be underway.

Keywords: Al-Sn alloy; Microstructure; Mechanical properties; Tribological properties
\end{abstract}

\section{Mini Review}

Al-Sn is an immiscible alloy and it is called as soft tribological alloy [1]. The alloy is widely used in engineering applications as antifriction and self-lubricant material. Moreover, Al-Sn alloys are considered as potential candidate lead free materials for advanced bearings in automotive and tribological applications [1,2]. The best required properties such as good conformability, friction reduction, embeddability, seizure resistance and corrosion resistance are essential to select Al-Sn alloys as engine bearing materials [2]. $\mathrm{Sn}$ is an important component of the alloy because it forms films preventing a seizure of Al with a steel shaft on the friction surface. Therefore, the Sn concentration in alloys should be higher and its distribution is more uniform [3]. Though, the solid solubility limit of $\mathrm{Sn}$ in $\mathrm{Al}$ is below $0.09 \mathrm{w} \% \mathrm{Sn}(0.02 \mathrm{at} \% \mathrm{Sn})$ [4], it is very difficult to achieve homogeneous distribution of $\mathrm{Sn}$ in $\mathrm{Al}$ matrix [5]. This is due to, high density difference between $\mathrm{Al}(2.7 \mathrm{~g} / \mathrm{cm} 3)$ and $\mathrm{Sn}$ $(7.2 \mathrm{~g} / \mathrm{cm} 3)$ metals. Moreover, there will be sedimentary tendency in the casting of Al-Sn alloy. Therefore, to improve the homogeneity of Sn phase in Al-Sn alloys, novel techniques such as physical vapor deposition, powder metallurgy, rapid solidification, severe plastic deformation, electro deposition and ternary alloying elements have been adopted by the researchers [1-6]. However, only few researchers have investigated the mechanical alloying method to produce controlled homogenous and refined microstructure in addition to adding ternary alloying elements in the immiscible AlSn alloy. This mini review briefly summarizes the effect of alloying element on the mechanical and tribological properties of $\mathrm{Al}-\mathrm{Sn}$ alloys.

\section{Effect of Alloying Element Addition to Al-Sn Alloys}

\section{Effect of Bi addition}

Isai Rosales et al. [7] investigated the mechanical properties and tribological behavior of Bi effect on Al-Sn Alloys. Al-Sn alloys were produced by the induction melting method with different $\mathrm{Bi}$ additions. Compositions of alloys used were Al-Sn (1-5at\%)-Bi(0.54at\%). Researchers reported that, addition of 3.5at.\% Bi exhibited increment in the plasticity of the alloys at least twice in comparison with the unalloyed sample. Significant increment in the toughness value was observed with 3.0at.\% Bi with an increment of 50\% compared to pure Al. Improvement of properties was attributed to the refinement of Al grains. Microstructure revealed the presence of bismuth along with $\mathrm{Sn}$ in the form of a continuous dispersed network along the grain boundaries of $\mathrm{Al}$ matrix as shown Figure 1. It was also highly recommended the use of these alloys in parts exposed to a constant friction and a moderate flexural stresses. However, addition of Bi slightly affected the tribological behavior.

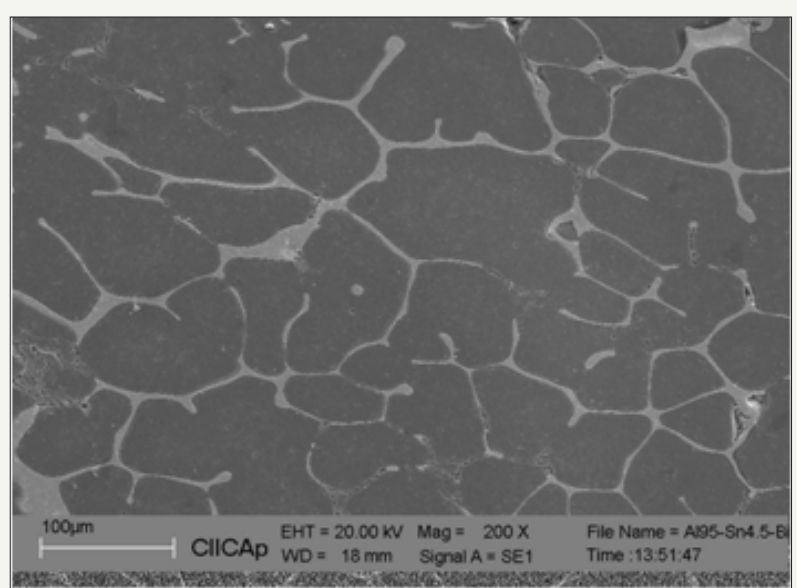

Figure 1 : Microstructure of the surface sample of the alloy with $3.5 a t . \% \mathrm{Bi}$ in annealing condition [7]. 


\section{Effect of Mg addition}

An effect and mechanism of $\mathrm{Mg}$ addition on the microstructure and tribological properties of the dual-scale Al-Sn alloys was investigated by $\mathrm{Lu}$ et al. [2]. The Al-12wt\%Sn-(0.5-2.0wt\%) $\mathrm{Mg}$ alloys were produced by powder metallurgy route. Figure 2 shows the SEM image of the $\mathrm{Al}-12 \mathrm{Sn}-2.0 \mathrm{Mg}$ alloy. The addition of $\mathrm{Mg}$ increased wet-ability of $\mathrm{Al}$ and $\mathrm{Sn}$ by disrupting the $\mathrm{Al}$ oxide film on nanocrystalline powder and improved Sn phase distribution. $\mathrm{Mg}$ addition exhibited better mechanical and tribological properties. However, researchers reported that, excessive Mg addition being up to $2.0 \mathrm{wt} \%$ resulted in poor wear resistance because the ductility of the alloys was decreased. Even wet-ability of alloy worsened due to high amount of $\mathrm{Mg}_{2} \mathrm{Sn}$ and $\mathrm{Al}_{12} \mathrm{Mg}_{17}$ phases due to excessive addition of MG.

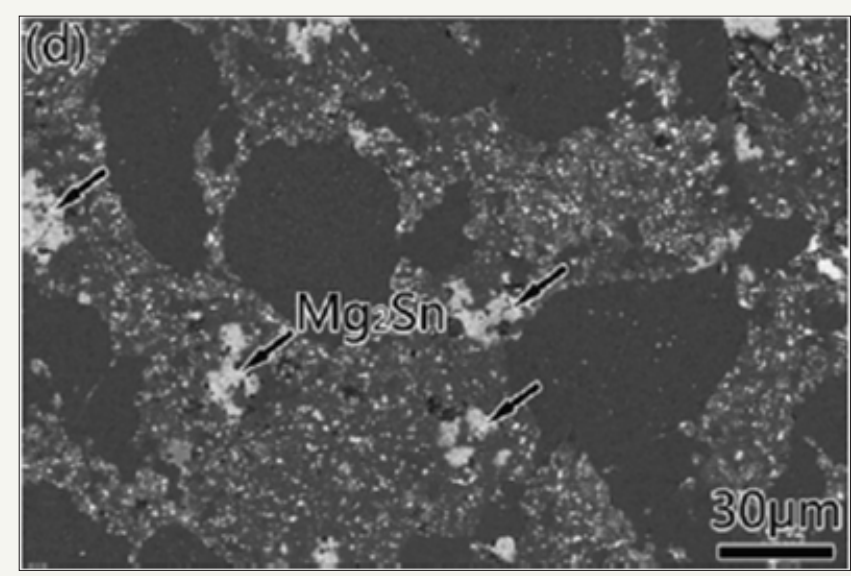

Figure 2 : SEM images of CG-30Al-12wtSn alloys with $2.0 \mathrm{Mg}$ addition after sintering at $873 \mathrm{~K}$ for $1 \mathrm{~h}[2]$.

\section{Effect of Si addition}

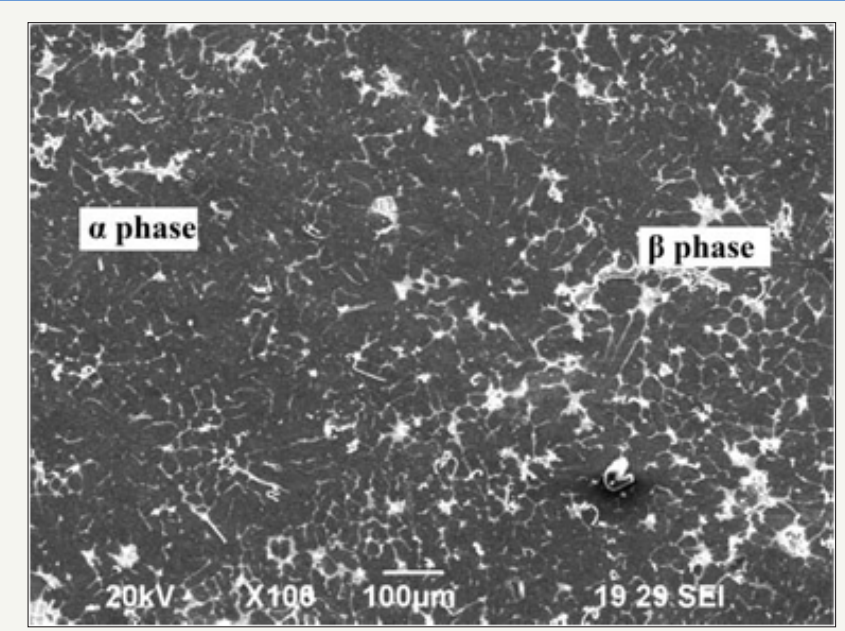

Figure 3 : Microstructure of Al-Sn-Si alloy [6].

The mechanical and tribological characteristic of Al-Sn-Si alloy was investigated using a pin-on-disc tribometer by Rameshkumar \& Rajendran [6]. The disc material was Al-based alloy with chemical composition (in wt\%): 9.0-12.5\%Sn, 0.8-1.25\% Cu, max $2.7-3.35 \%$ $\mathrm{Si}$, and the remainder $\mathrm{Al}$. The friction and wear behavior of the alloy sliding against high carbon-high chromium steel was investigated at different loads $(50,60,70$, and $75 \mathrm{~N})$ at a constant sliding speed of $1 \mathrm{~m} / \mathrm{s}$. Figure 3 shows SEM image of Al-Sn-Si alloy. Si particles surrounded by soft Sn phase in Al matrix augmented wear and antifrictional properties of alloy. The hardness properties improved with $\mathrm{Si}$ addition resulting in better mechanical properties.

Researchers reported that, hardness values increased with the addition of $\mathrm{Si}$ (1.364 times more than pure $\mathrm{Al}$ and 1.224 times more than an Al-Sn alloy. Al-Sn-Si alloy exhibited little wear. The wear characteristics of the newly developed alloy under lubricated conditions were better than those of the Al-Sn alloy.

\section{Effect of $\mathrm{Cu}$ addition}

The structure and properties of the Al-20wt.\%Sn-1wt.\%Cu ternary bearing alloys were studied and analyzed under different cold rolling reduction mechanism at rates of $24 \%, 40 \%, 56 \%$ and $72 \%$ by Nassar et al. [8]. The microhardness (Hv) increased with increasing cold rolling reduction rate till $56 \%$ and then decreased at $72 \%$. With increase in temperature, thermal expansion coefficient (TEC) was increased. However it was reported that mismatch of TEC between $\mathrm{Al}_{2} \mathrm{Cu}$ and $\mathrm{Sn}$ may develop an internal stresses which leads to generation of cracks. Cold rolling has a negative impact on electrical conductivity due to the rupture of lattice structure which obstacle the electron flow.

\section{Effect of $\mathrm{Pb}$ addition}

Noskova et al. [9] investigated the mechanical and tribological properties of $\mathrm{Al}-30 \mathrm{Sn}, \mathrm{Al}-25 \mathrm{Sn}-15 \mathrm{~Pb}$ and $\mathrm{Al}-5 \mathrm{Sn}-35 \mathrm{~Pb}$ alloys after equichannel angular pressing at a load of $400 \mathrm{kN}$ and shear under a pressure of $5 \mathrm{GPa}$. Addition of $\mathrm{Pb}$ in the alloy increased the hardness. Though $\mathrm{Pb}$ can be considered as an alloying element due to its toxicity researchers are diverting toward $\mathrm{Pb}$ free materials.

Based on available literature survey, still enormous of work at to be carried out on mechanical and tribological properties to recognize above specified alloys to support heavy load, speed and reliability in engineering applications An alternative way to reach this requirement can be the alloying with third elements such as $\mathrm{Ni}$ and Co. however the effect of these ternary element on Al-Sn are not known and also effect of heat treatment and cooling rate on alloy not focused by other researchers. It is recommended that the future work should focus on investigating effect of nickel and cobalt as ternary alloying element addition to Al-Sn alloys. Further influence of $\mathrm{Ni}$ and Co addition on the microstructure and tribological properties of Al-Sn alloys are essential for further research.

\section{Conclusion}

Current review provides an important basis for understanding of influence of ternary element such as $\mathrm{Bi}, \mathrm{Mg}, \mathrm{Si}, \mathrm{Cu}, \mathrm{Pb}$ on microstructural, mechanical properties and tribological properties of Al-Sn alloys. the highlights are, Bi refines grain structure improves mechanical properties, $\mathrm{Mg}$ reduces coarsening of $\mathrm{Sn}$ and enhances mechanical and tribological properties, Si increases wear resistance and hardness property of the alloy, the microhardness increased with increasing cold rolling reduction rate till $56 \%$ and 
then decreased at $72 \%$ in presence of $\mathrm{Cu}$ and addition of $\mathrm{Pb}$ in the alloy increased the hardness. However, influence of $\mathrm{Ni}$ and $\mathrm{Co}$ addition on the microstructure and tribological properties of Al-Sn alloys are essential for further research.

\section{References}

1. Schouwenaars R, Jacobo VH, Ortiz A (2007) Microstructural aspects of wear in soft tribological alloys. Wear 263(1-6): 727-735.

2. Lu ZC, Gao Y, Zeng MQ, Zhu M (2014) Improving wear performance of dual-scale Al-Sn alloys: the role of Mg addition in enhancing $\mathrm{Sn}$ distribution and tribolayer stability. Wear 309(1-2): 216-225.

3. Rusin NM, Skorentsev AL, Korosteleva EN (2012) Tribotechnical properties modification of Al-Sn alloys by ECAP. In Strategic Technology (IFOST), $7^{\text {th }}$ International Forum, IEEE, pp. 1-3.

4. Abed EJ (2012) Study of solidification and mechanical properties of AlSn casting alloys. Asian Transaction on Engineering 2(3): 89-98.
5. Abed EJ (2014) Rapidly solidified of hyper eutectic aluminum-silicon alloys ribbons by using melt-spinning techniques. International Journal of Current Engineering and Technology 4(3): 1394-1398.

6. Rameshkumar T, Rajendran I (2013) Mechanical and tribological properties on Al-Sn-Si alloy-based plain bearing material. Tribology Transactions 56(2): 268-274.

7. Rosales I, Rodriguez GG, Gama JL, Guardian R (2014) Bismuth effect on the mechanical properties of antifriction Al-Sn alloys. Materials Sciences and Applications 5(5): 330-337.

8. Nassar A, Taha AS, Labeeb A, Gouda ESA (2015) Structure and properties of the Al-Sn-Cu bearing alloy under different cold rolling Conditions. Journal of Materials Science and Engineering B 5(7-8): 298-304.

9. Noskova NI, Korshunov LG, Korznikov AV (2008) Microstructure and tribological properties of $\mathrm{Al}-\mathrm{Sn}, \mathrm{Al}-\mathrm{Sn}-\mathrm{Pb}$, and $\mathrm{Sn}-\mathrm{Sb}-\mathrm{Cu}$ alloys subjected to severe plastic deformation. Metal science and heat treatment 50(11): 593-599.
Creative Commons Attribution 4.0 International License

For possible submissions Click Here

\section{Submit Article}

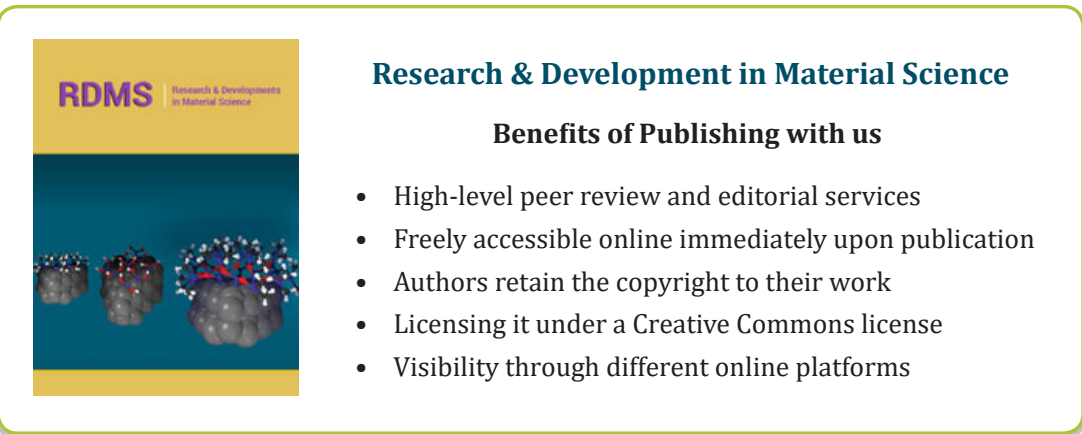

